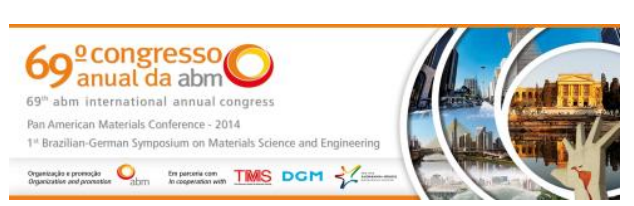

Tema: Gestão de Manutenção

\title{
COMO ESTRUTURAR A EMPRESA ANTES DE PENSAR NA IMPLANTAÇÃO DE UM SISTEMA DE GESTÃO DE ATIVOS CONFORME ABNT ISO 55001*
}

\section{Resumo}

Ricardo Tadeu Meneses Sodré1

Principalmente após a crise mundial de 2008, as grandes empresas brasileiras focaram na redução de custo como fator de sobrevivência, buscando manter, em contrapartida a produtividade e qualidade dos produtos. As normas brasileiras ABNT NBR ISO 55000/1/2, combinam atividades sistemáticas, coordenadas e práticas pelas quais uma organização gerencia de forma organizada e sustentável seus ativos tangíveis e intangíveis e sistemas, seu desempenho, bem como seus riscos e custos associados. A norma trata do ciclo completo do ativo, desde a concepção até o seu descarte. A implantação de uma norma deste porte requer compromisso de toda organização, principalmente da alta direção, no intuito de correlacionar os objetivos do negócio com as atividades de manutenção. O ponto principal é entender que a Manutenção é parte de um ciclo mais amplo que trata de todo o ciclo de vida do ativo, logo a Manutenção está contida dentro da Gestão de Ativos. O trabalho visa mostrar de maneira prática como a ArcelorMittal Tubarão está se estruturando para uma implantação futura da ABNT NBR ISO 5500X. Tal estruturação engloba atividades estratégicas, táticas e operacionais de alto nível visando à elevação da maturidade em Gestão de Ativos.

Palavras-chave: Sistema de gestão de ativos; ABNT 55000; Gestão de ativos.

\section{HOW TO STRUCTURE THE COMPANY BEFORE CONSIDERING AN ASSET MANAGEMENT SYSTEM DEPLOYMENT ACCORDING TO ISO 55001}

\section{Abstract}

Mainly after the 2008 worldwide crisis, the large Brazilian companies were focused on cost reduction as a survival factor, keep looking for, however the productivity and products quality. Brazilian standards ABNT NBR ISO 55000/1/2 combine systematic, coordinated and practices activities through which an organization manages in an organized and sustainable way its tangible and intangible assets and systems, its performance, as well as its risks and associated costs. The standard addresses the complete asset cycle, from conception to disposal. The implementation of a standard of this magnitude requires commitment from the entire organization, especially of the top management, in order to correlate the business objectives with the maintenance activities. The main point is understand the maintenance as part of a larger cycle that considers the whole asset life cycle, so the maintenance is contained within the Asset Management. This work aims to show, in a practical way, how the ArcelorMittal Tubarão is organizing for future ISO 5500X implementation. This structuration encompasses strategic, tactical and operational high-level activities that aimed the Asset Management maturity elevation.

Keywords: Asset management system; ISO 55000; Asset management.

1 Engenheiro Mecânico, Especialista em Engenharia de Manutenção e de Materiais, Mestre em Fadiga e Mecânica de Fratura, Membro do comité CEE251 de criação da norma ABNT NBR ISO $5500 x$ e do IAM (Institute of Asset Management), Engenheiro especialista em Manutenção e Gestão de Ativos, Gerência de Tecnologia de Manutenção, ArcelorMittal Tubarão, Vitória/ES, Brasil.

\footnotetext{
* Contribuição técnica ao $69^{\circ}$ Congresso Anual da ABM - Internacional e ao 14ํㅡㄹ ENEMET - Encontro Nacional de Estudantes de Engenharia Metalúrgica, de Materiais e de Minas, 21 a 25 de julho de 2014, São Paulo, SP, Brasil.
} 


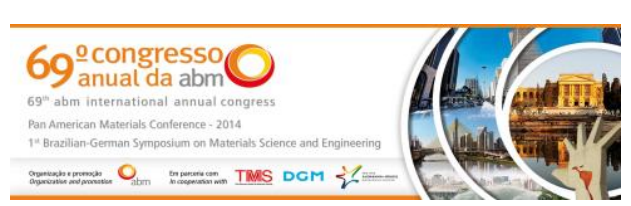

\section{INTRODUÇÃO}

De uma maneira macro a Manutenção de Classe Mundial consiste na melhoria de modo constante e estruturado, com foco em estar ou se manter no primeiro quartil das melhores empresas do mundo [1]. As normas de Gestão de Ativos ABNT NBR ISO 55000, 55001 e 55002, lançadas em Janeiro de 2014, combinam atividades sistemáticas, coordenadas e práticas pelas quais uma organização gerencia de forma organizada e sustentável seus ativos tangíveis e intangíveis e sistemas, seu desempenho, bem como seus riscos e custos associados. A norma trata do ciclo completo do ativo, desde a concepção ate o seu descarte, ou seja, a Manutenção é parte de um ciclo mais amplo de Gestão de Ativos [2], Figura 1.

Para a Gestão de Ativos é fundamental o processo de tomada de decisões baseado em avaliações de riscos quantitativas, com fatos e dados que permitam aferir a qualidade dos ativos em momentos determinados, que conduzam à decisões bem informadas e detalhadas. Um dos conceitos básicos de Gestão de Ativos envolve a possibilidade de colocar "o mundo da Manutenção" em contato com "o mundo das finanças" [3].

A ArcelorMittal Tubarão decidiu implantar uma série de ações com foco na melhoria do resultado operacional da empresa e que certamente serve de preparação para uma implantação futura da norma ABNT NBR ISO 55001 [4], com o intuito de se manter entre as melhores empresas do mundo.

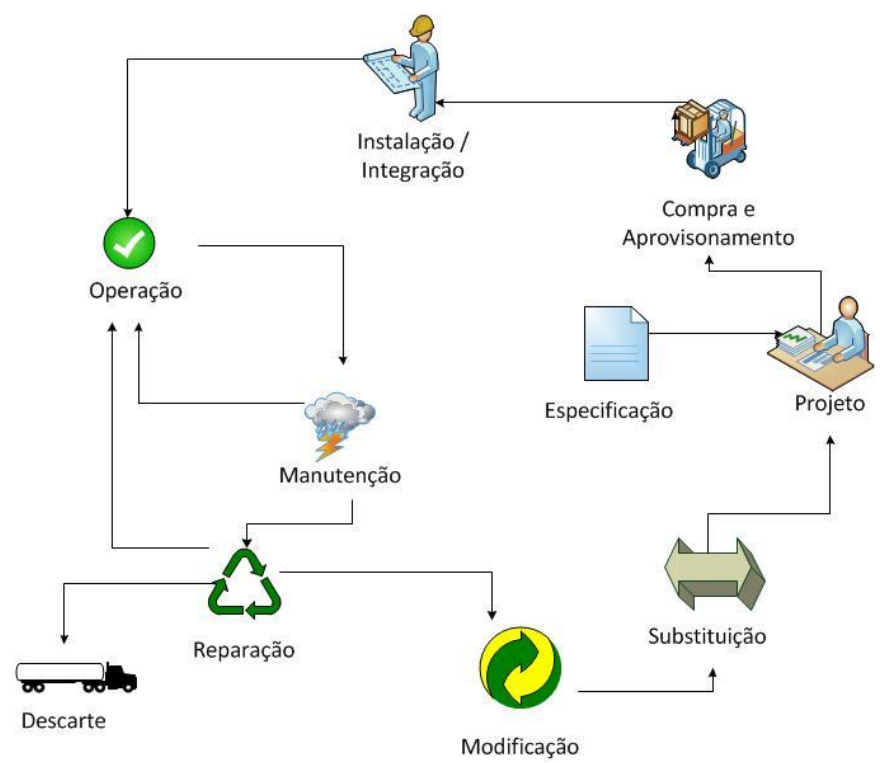

Figura 1. Ciclo de abrangência da Gestão de Ativos.

\section{A ARCELORMITTAL TUBARÃO}

A ArcelorMittal Tubarão, ex Companhia Siderúrgica de Tubarão (CST), maior produtora mundial de semi-acabados de aço, foi constituída em junho de 1976, como uma joint-venture de controle estatal. Porém a sua operação começou em novembro de 1983.

Nesse período, a companhia criou e consolidou sua liderança no mercado, passando por profundas transformações, intensificadas após a privatização em 1992. A partir daí, a Companhia passou a ser controlada por grupos nacionais e estrangeiros.

\footnotetext{
* Contribuição técnica ao $69^{\circ}$ Congresso Anual da ABM - Internacional e ao 14ํㅡㄹ ENEMET - Encontro Nacional de Estudantes de Engenharia Metalúrgica, de Materiais e de Minas, 21 a 25 de julho de 2014, São Paulo, SP, Brasil.
} 


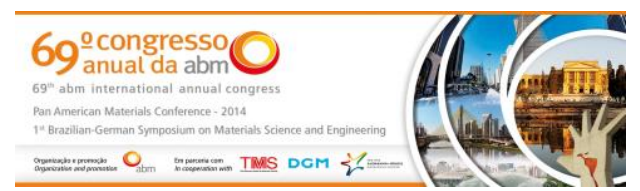

A Companhia diversificou a sua produção, em 2002, com a implantação de um Laminador de Tiras a Quente (LTQ), que incorpora a mais avançada tecnologia disponível no mercado. Já em 2004, consolida a otimização da sua produção para 5 milhões de toneladas/ano (placas e bobinas), com a finalização da montagem da Central Termelétrica 4, o que garante também a auto-suficiência energética, mesmo com a operação do LTQ.

Em 2003, teve início o Plano de Expansão da produção para 7,5 milhões de toneladas/ano.

As obras de expansão, que envolvem alta tecnologia e eficiente sistema de controle ambiental começaram em 2004. No mesmo ano, acontece a consolidação do modelo energético com a entrada em operação da Central Termelétrica 4 e do sistema de Recuperação de Gás.

Em outubro de 2005 é criada a Arcelor Brasil. Resultado da união da Companhia Siderúrgica Belgo Mineira, da CST e da Vega do Sul, a Arcelor Brasil já nasce como um dos maiores grupos industriais do Brasil e com capacidade anual de produção de 11 milhões de toneladas de aço. No mesmo ritmo de crescimento, a companhia alcançou a Certificação do Sistema de Gestão de Segurança e Saúde de acordo com a Norma OHSAS 18001.

Em Junho de 2006, a Arcelor e suas subsidiárias passaram a fazer parte do grupo ArcelorMittal, como consequência da fusão entre a Arcelor e a Mittal.

A Expansão da ArcelorMittal Tubarão iniciou sua operação em 2007. Com um investimento de US\$ 1 bilhão, foram construídas novas unidades produtivas, que elevaram a capacidade de produção de 5 para 7,5 milhões de toneladas por ano de aço - placas e bobinas a quente, recuperando, assim, a participação da empresa no mercado siderúrgico internacional.

Em 2009, com investimento da ordem de US\$120 milhões, a empresa inaugurou a expansão do Laminador da Tiras a Quente. A ampliação contemplou a instalação de um novo forno de reaquecimento de placas, permitindo à ArcelorMittal Tubarão ampliar sua capacidade de produção de 2,8 para 4 milhões de toneladas de bobinas a quente por ano [5].

\section{CENÁRIO DA ARCELORMITTAL TUBARÃO}

Principalmente após a crise mundial de 2008, as grandes empresas brasileiras focaram na redução de custo como fator de sobrevivência, buscando manter, em contrapartida a produtividade e qualidade dos produtos.

O mercado siderúrgico nacional sofreu forte retração nessa época. No caso específico da ArcelorMittal Tubarão, até 2008 o mercado estava favorável, a mão de obra estava bem treinada e composta de pessoas experientes, recursos estavam disponíveis e a indústria estava em plena expansão. Após o estouro da crise mundial até o final de 2012 o mercado siderúrgico nacional e internacional ficou desfavorável, limitando recursos que forçaram a redução de produção. Paralelamente a crise houve uma forte perda de mão de obra capacitada para o mercado. A partir do final de 2012 e início de 2013 o mercado siderúrgico inicia sua recuperação o que traz para as empresas um grande desafio por resultados para retomada do mercado e crescimento sustentável, logo o foco está na otimização de recursos, desenvolvimento de pessoas, e implantação de estratégias de ponta visando buscar resultados que sustentem o processo produtivo e perenizem a empresa, Figura 2.

\footnotetext{
* Contribuição técnica ao $69^{\circ}$ Congresso Anual da ABM - Internacional e ao 14ํㅡㄹ ENEMET - Encontro Nacional de Estudantes de Engenharia Metalúrgica, de Materiais e de Minas, 21 a 25 de julho de 2014, São Paulo, SP, Brasil.
} 

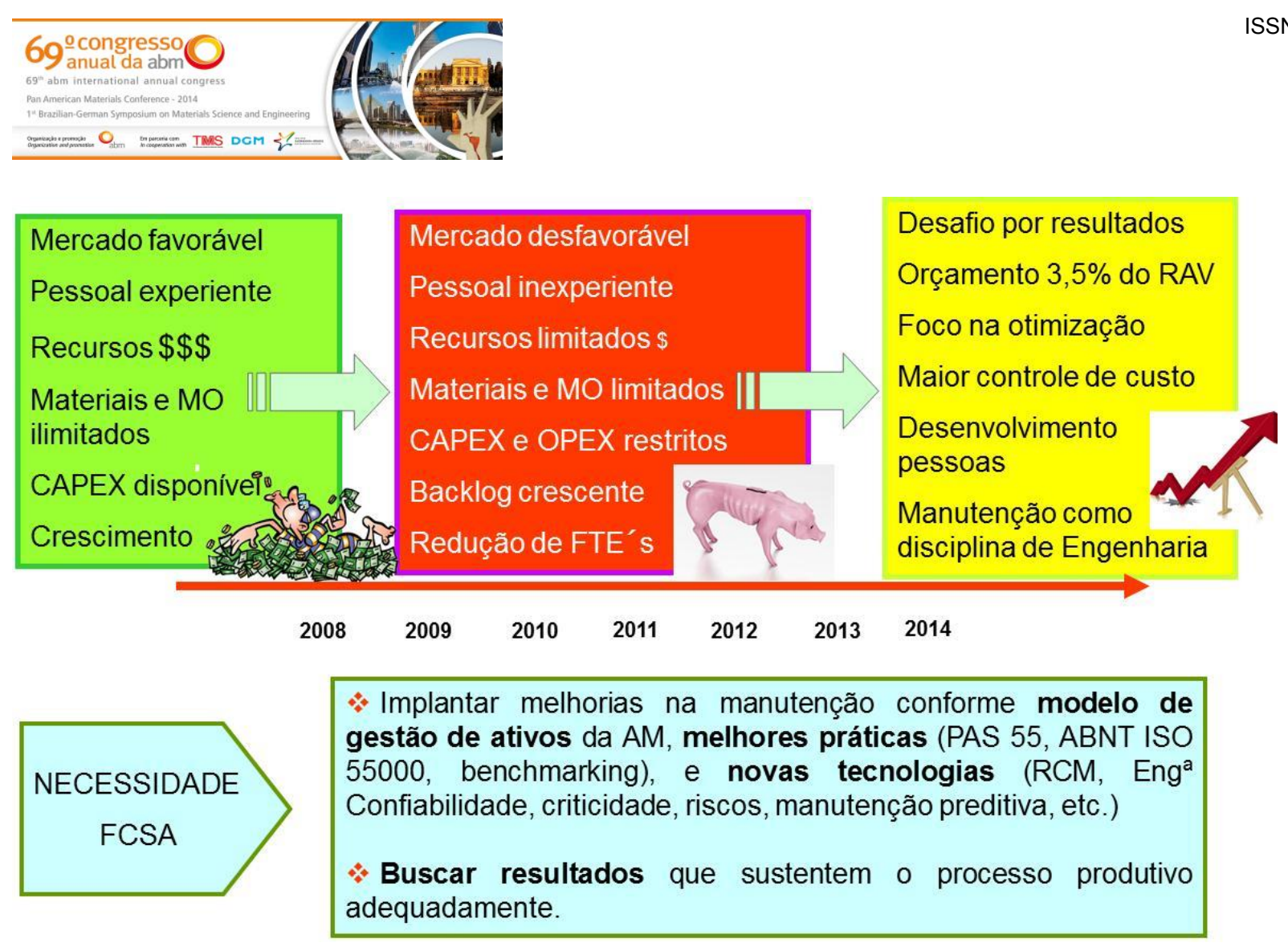

Fonte. FCSA (Flat Carbon South America - Aços Planos América do Sul).

Figura 2. Cenário macro-econômico e estratégias da ArcelorMittal Tubarão.

\section{MATERIAIS E MÉTODOS}

Visando o retorno a excelência, o primeiro passo dado pela ArcelorMittal Tubarão foi desenvolver e estabelecer um Plano Diretor de Manutenção e Gestão de Ativos que conecte os objetivos estratégicos organizacionais, incluindo objetivos de curto e longo prazo, com contém atividades do dia a dia da Manutenção e Gestão de ativos. Esse plano diretor as diretrizes corporativas de "o que" fazer e "como" fazer e vale para todas as empresas da ArcelorMittal pertencentes ao FCSA (Flat Carbon South America- Aços Planos América do Sul), Figura 3.

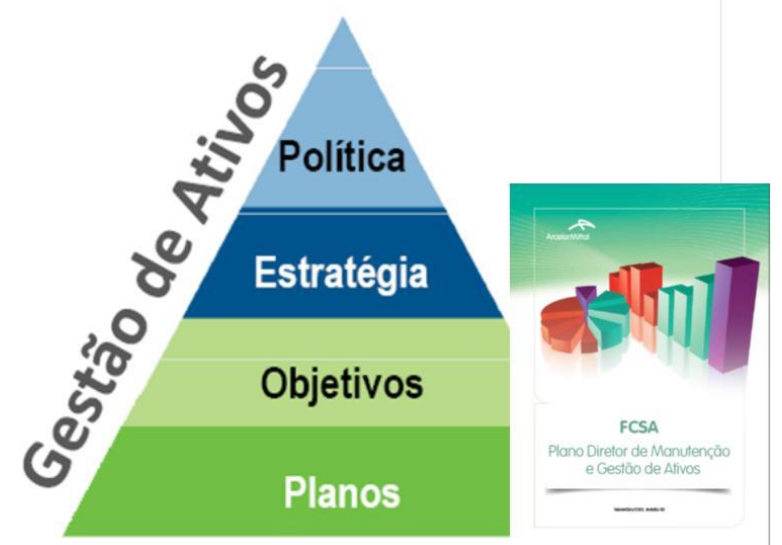

Figura 3. Plano diretor de Manutenção e Gestão de Ativo conectado aos objetivos estratégicos do FCSA.

Como visão geral, o Plano diretor de Manutenção e Gestão de Ativos, está estruturado em atividades estratégicas, táticas e operacionais de alto nível visando à elevação da maturidade da companhia em Gestão de Ativos, primeiramente com

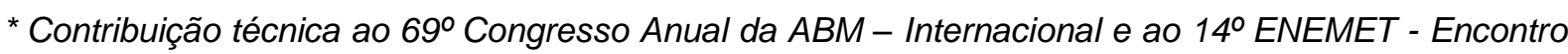
Nacional de Estudantes de Engenharia Metalúrgica, de Materiais e de Minas, 21 a 25 de julho de 2014, São Paulo, SP, Brasil.
} 


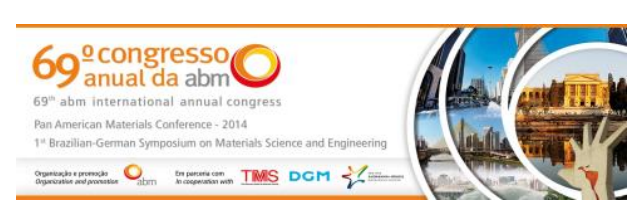

foco nas atividades diretamente relacionadas a Manutenção. Aborda o desdobramento da Política de Manutenção e Gestão de Ativos em objetivos, diretrizes e ferramentas, passando a ser um guia para as áreas diretamente ligadas ao tema, Figura 4.

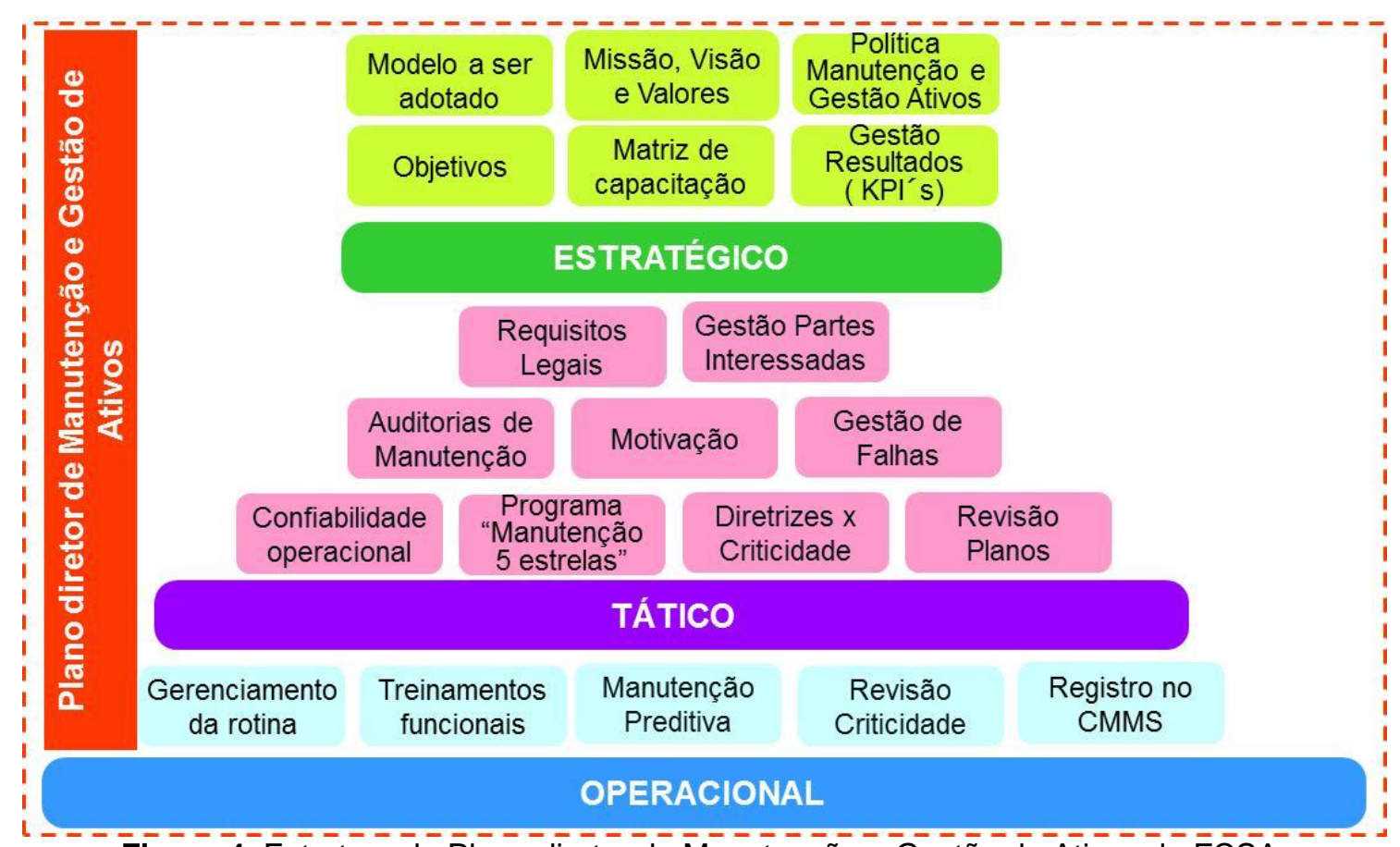

Figura 4 . Estrutura do Plano diretor de Manutenção e Gestão de Ativos da F $\bar{F} \bar{C} \overline{S A}$.

\subsection{Aspectos Estratégicos}

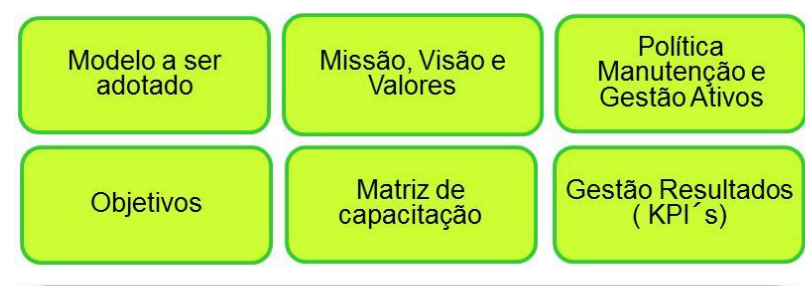

ESTRATÉGICO

Figura 5. Aspectos estratégicos do Plano diretor da Manutenção da FCSA.

Seis temas são tratados como aspectos estratégicos, Figura 5.

O modelo de manutenção da ArcelorMittal Tubarão e ArcelorMittal Vega (FCSA) seguem as diretrizes definidas pelo GMT (Global Maintenance Team) que são válidas para todo o grupo ArcelorMittal.

O Processo de Confiabilidade dos ativos preserva e melhora gradativamente a capacidade dos ativos para satisfazer os requisitos de desempenho ao melhor custo, sendo que a Excelência em Manutenção é atingida após a consolidação de valores fundamentais, Figura 6.

A pirâmide mostra os requisitos para se atingir a Excelência em Manutenção, incluindo:

- Requisitos básicos focados no estabelecimento de uma abordagem sistemática para gerenciar e executar a manutenção.

\footnotetext{
* Contribuição técnica ao $69^{\circ}$ Congresso Anual da ABM - Internacional e ao 14ํㅡㄹ ENEMET - Encontro Nacional de Estudantes de Engenharia Metalúrgica, de Materiais e de Minas, 21 a 25 de julho de 2014, São Paulo, SP, Brasil.
} 
- Requisitos de alto nível incorporando ferramentas e técnicas para aumentar o desempenho e a confiabilidade dos ativos.

- Liderança comprometida e gestão pró-ativa.

Não é necessário satisfazer a todos os requisitos de um nível para iniciar os requisitos de um nível mais alto. No entanto, todos os requisitos devem estar implantados para atingir e sustentar a Excelência em Manutenção.

A gestão pró-ativa da manutenção é atingida através da interação dos processos de confiabilidade dos ativos, infraestrutura, práticas e abordagem de implementação.

- Itens destacados em amarelo estão relacionados aos fundamentos do Processo de Confiabilidade dos Ativos e devem ser colocados em prática prioritariamente.

- Itens destacados em marrom estão relacionados à infraestrutura e engloba as ferramentas relacionadas ao CMMS (Sistema computadorizado de gerenciamento da manutenção) que suportam a execução do Processo de Confiabilidade dos Ativos. A ferramenta mais importante é o próprio CMMS. É fundamental que ele esteja alinhado com todo o processo.

- Itens destacados em verde são as melhores práticas (ferramentas, metodologias e abordagens) que suportam o processo.

- Itens destacados em azul são os requisitos que suportam a abordagem de implantação. Esses requisitos otimizam a estrutura organizacional, trazendo clareza dos papéis e responsabilidades e aumentando a competência dos empregados.

Baseado neste modelo foi criado a missão, a visão e valores a serem seguidos pelas áreas envolvidas na gestão de ativos. Uma politica, diretamente ligada aos objetivos organizacionais, foi criada e desdobrada em objetivos palpáveis até o "chão de fábrica", Figura 7.

Um dos pilares fundamentais para suportar o resultado da empresa são os recursos humanos capacitados [6]. Neste contexto foram definidas as competências necessárias para cada função da manutenção e os treinamentos necessários. As premissas básicas foram:

- Definição de matriz de capacitação padrão

- Treinamento de 150 supervisores na ferramenta

- Utilização de instrutores internos $\rightarrow$ Baixo custo.

- Foco nos itens que causam maior incidência de falhas.

- Treinamentos curtos e práticos.

- Treinamento personalizado $\rightarrow$ Só treina na competência não dominada.

- Acompanhamento via auditoria da evolução do pessoal.

Para garantir o controle e acompanhamento da evolução dos resultados, foram definidos corporativamente os indicadores para medição de todo o processo de manutenção e o resultado da manutenção para que cada gerente possa fazer a gestão individualizada de sua área. Indicadores de alto nível foram definidos para a alta gestão da empresa.

\footnotetext{
* Contribuição técnica ao 69ำ Congresso Anual da ABM - Internacional e ao 14ํㅡㄹ ENEMET - Encontro Nacional de Estudantes de Engenharia Metalúrgica, de Materiais e de Minas, 21 a 25 de julho de 2014, São Paulo, SP, Brasil.
} 

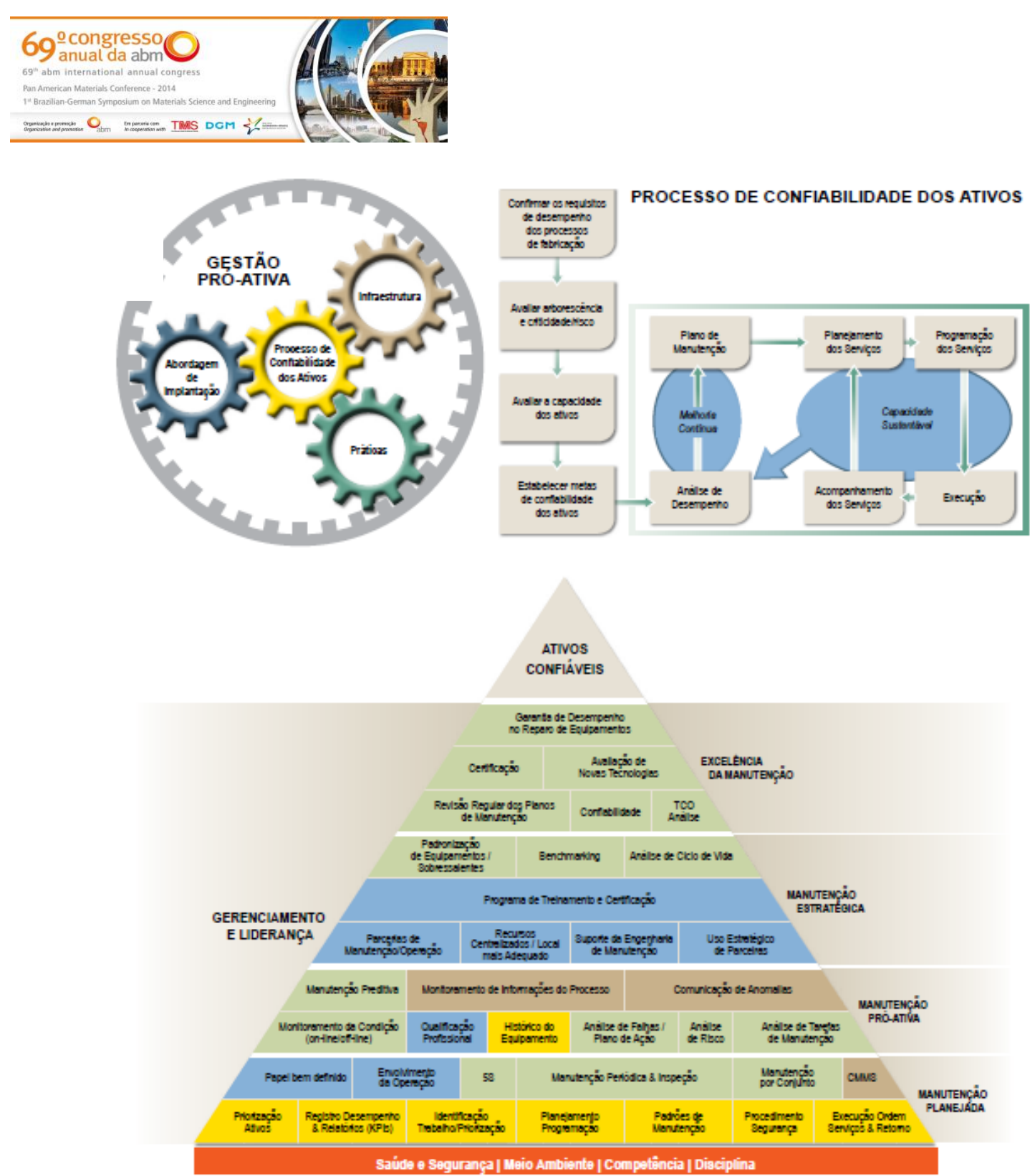

Figura 6. Modelo de Manutenção global definido pela ArcelorMittal.
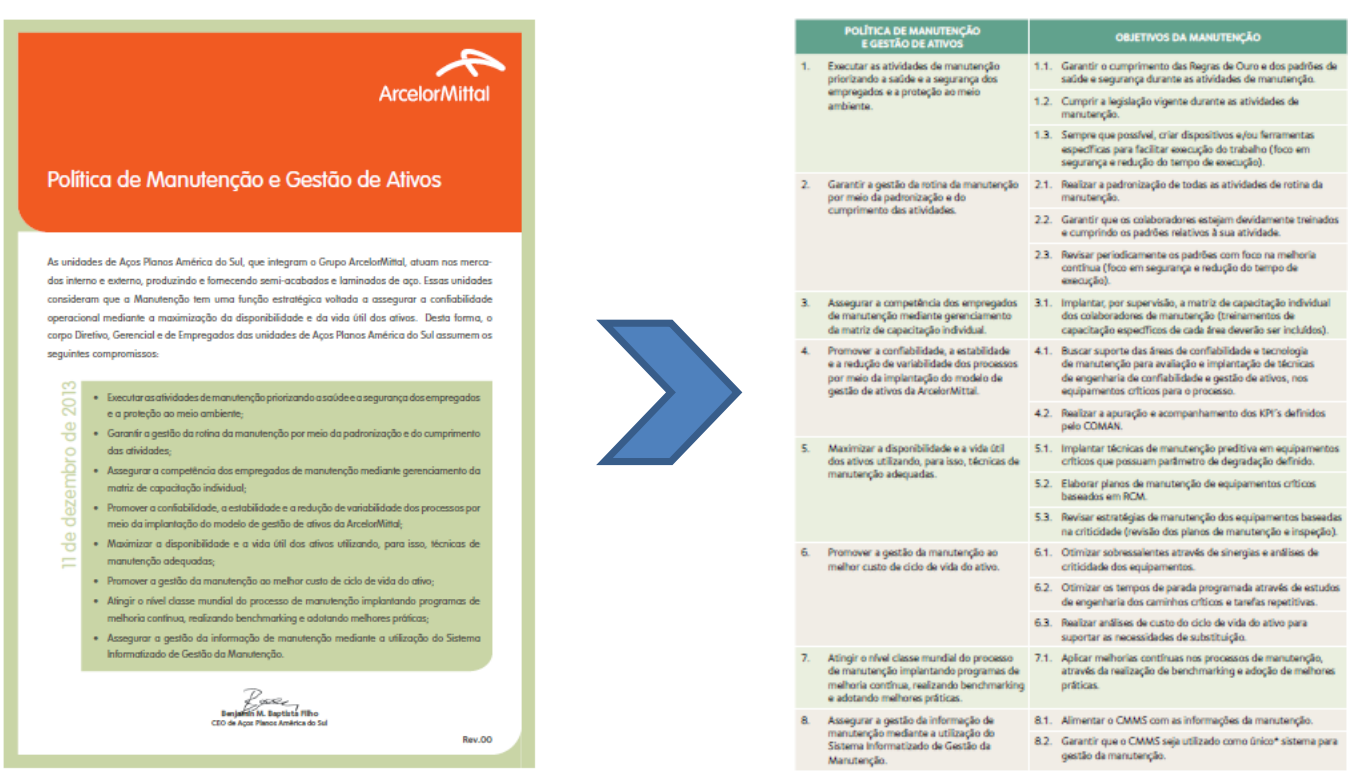

Figura 7. Política de Manutenção e Gestão de Ativos do FCSA desdobrado em objetivos palpáveis.

* Contribuição técnica ao 69 Congresso Anual da ABM - Internacional e ao 14ํㅡㄹ ENEMET - Encontro Nacional de Estudantes de Engenharia Metalúrgica, de Materiais e de Minas, 21 a 25 de julho de 2014, São Paulo, SP, Brasil. 


\subsection{Aspectos Táticos}

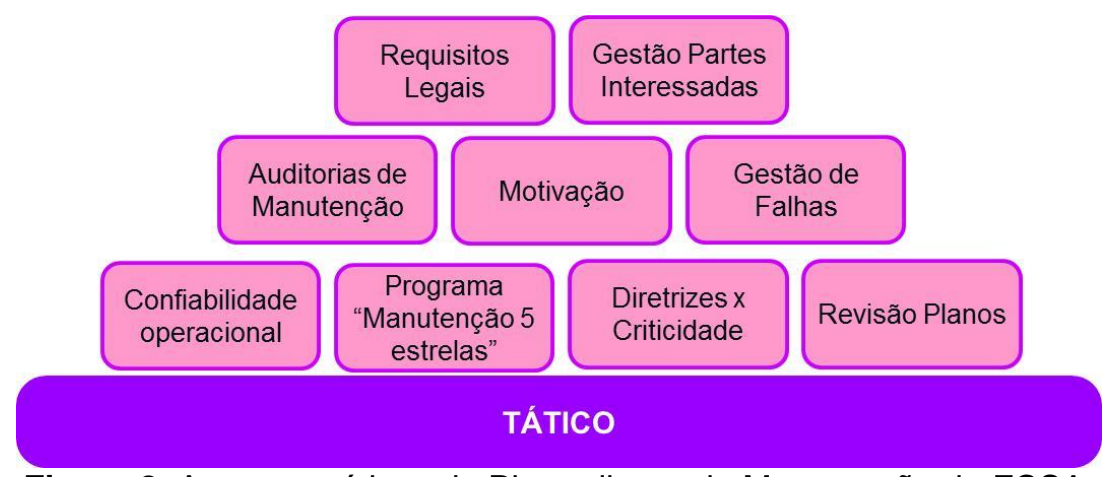

Figura 8. Aspectos táticos do Plano diretor da Manutenção do FCSA.

Nove temas são tratados como aspectos táticos, Figura 8.

Os requisitos legais são tratados como valor pelo FCSA, sendo parte integrante do dia a dia das áreas (valor para ArcelorMittal Tubarão).

As partes interessadas são reunidas bimestralmente para alinhamento de expectativas, comentário de resultados troca de experiências e revisão de estratégicas. As reuniões são coordenadas pelo Departamento de Manutenção Central.

Auditorias anuais das áreas de manutenção foram sistematizadas baseadas em 5 pilares considerados fundamentais pelo FCSA: Capacitação, CMMS, Planos de Inspeção, Planos de Manutenção e Gestão de Falhas. Este programa, chamado de "Manutenção 5 Estrelas" tem os principais objetivos:

- Consolidar os elementos fundamentais da manutenção.

- Nivelar conceitos e utilização de ferramentas de gestão da manutenção.

- Permitir trocas de "boas práticas" internas entre áreas de manutenção.

- Motivar as áreas de manutenção.

Para cada um dos elementos fundamentais da manutenção o programa subdivide em 48 temas, que são explorados através de questionário dirigido para avaliação da área de manutenção. Cada pergunta é dividida em requisitos que classificam o atendimento ao tema em iniciante, básico, intermediário e 5 estrelas. Com o objetivo de facilitar a implantação dos temas, foi elaborado um programa com todas as 48 perguntas, além dos seguintes questionamentos: "qual a importância de cada tema para a área de manutenção", "quem deveria estar envolvido" e "quais são as evidências típicas geradas pelas áreas que estão com o tema implantado". Vale lembrar que as perguntas foram baseadas nos requisitos corporativos da ArcelorMittal, no PAM (PAS 55 Assessment Methodology) [7], na norma ABNT NBR ISSO 55002 [8], além de experiências internas.

Após auditoria um plano de ação é traçado para as oportunidades de melhoria e as boas práticas são compartilhadas. Como fator motivacional a área recebe um certificado de participação com o resultado e premiação, Figura 9.

\footnotetext{
* Contribuição técnica ao 69ํ Congresso Anual da ABM - Internacional e ao 14ํㅡㄹ ENEMET - Encontro Nacional de Estudantes de Engenharia Metalúrgica, de Materiais e de Minas, 21 a 25 de julho de 2014, São Paulo, SP, Brasil.
} 

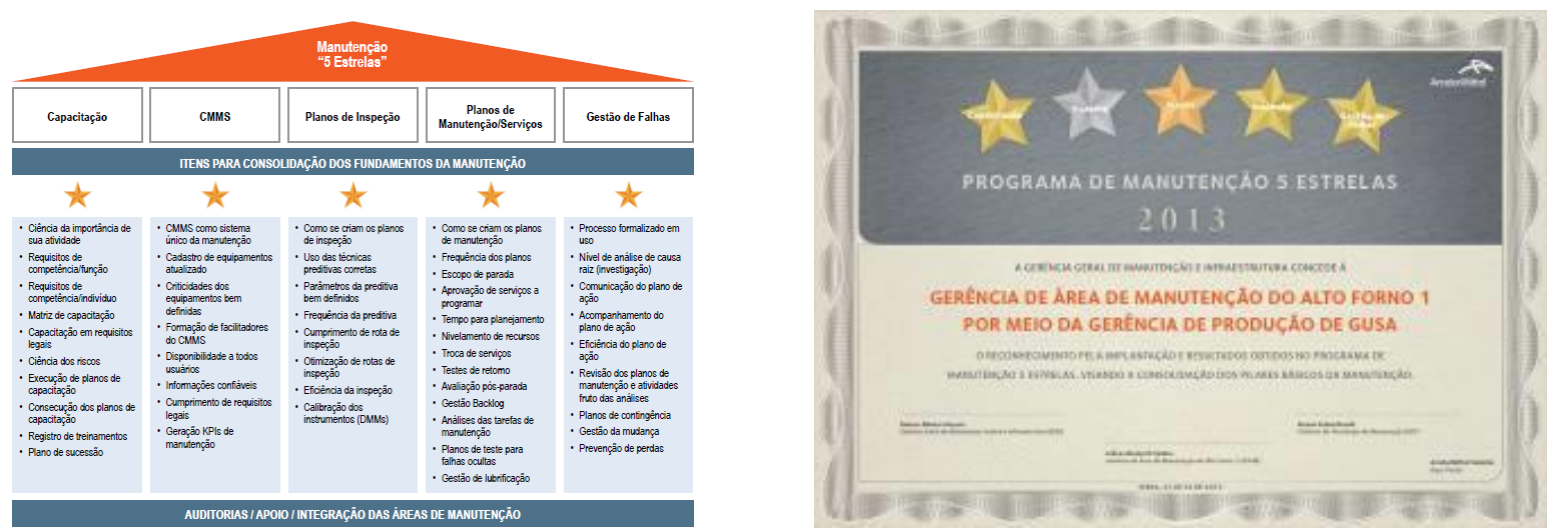

Figura 9. Pilares do programa "Manutenção 5 Estrelas e certificado de participação.

As diretrizes de manutenção e gestão dos ativos se baseiam na criticidade dos ativos. A criticidade é determinada de forma padronizada seguindo critérios padronizados. Esse critério de classificação de criticidade está inserido no CMMS. Para cada uma das faixas de criticidade "AA", "A", "B" ou "C" atingida após avaliação, critérios claros de "o que fazer" em relação aos planos de manutenção, monitoramento, gestão de falhas, sobressalentes, planos de contingência e inspeção sobre o aspecto do recurso humano, estão definidos, Figura 10.

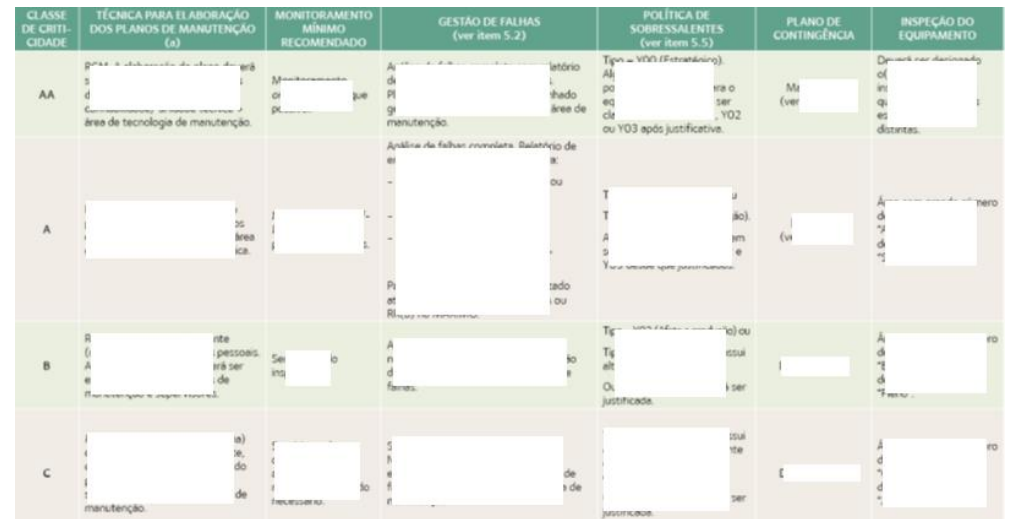

Figura 10. Diretrizes de Manutenção e Gestão de Ativos baseados na criticidade dos equipamentos.

A confiabilidade operacional é garantida através de utilização de confiabilidade quantitativa para criação e revisão de planos de manutenção dos equipamentos crítcos, além da utilização de confiabilidade qualitativa para análise dos dados de vida. Foi desenvolvido, pela ArcelorMittal Tubarão, um sistema próprio para tratar a confiabilidade qualitativa [9].

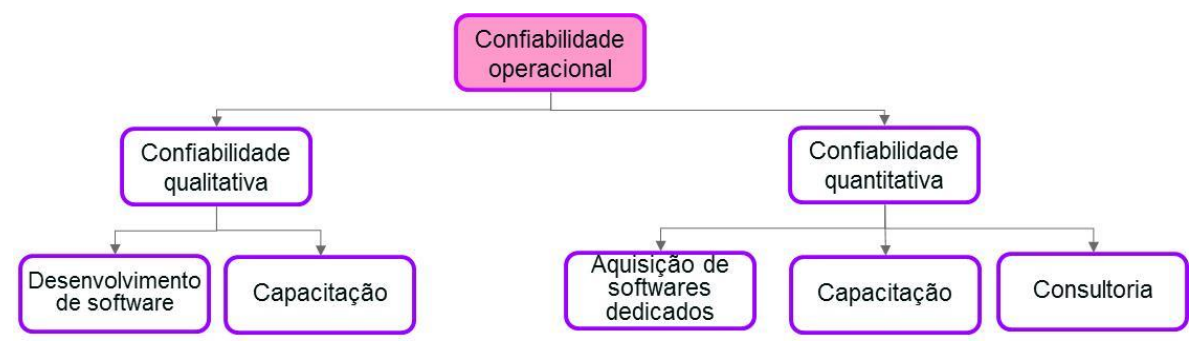

Figura 11. Abordagem de confiabilidade operacional do FCSA.

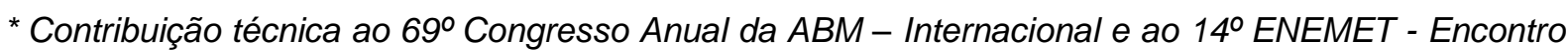
Nacional de Estudantes de Engenharia Metalúrgica, de Materiais e de Minas, 21 a 25 de julho de 2014, São Paulo, SP, Brasil.
} 


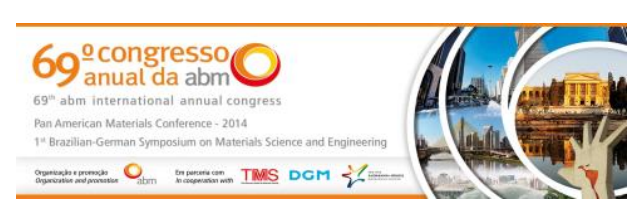

\subsection{Aspectos Operacionais}

\begin{tabular}{|c|c|c|c|c|}
$\begin{array}{c}\text { Gerenciamento } \\
\text { da rotina }\end{array}$ & $\begin{array}{c}\text { Treinamentos } \\
\text { funcionais }\end{array}$ & $\begin{array}{c}\text { Manutenção } \\
\text { Preditiva }\end{array}$ & $\begin{array}{c}\text { Revisão } \\
\text { Criticidade }\end{array}$ & $\begin{array}{c}\text { Registro no } \\
\text { CMMS }\end{array}$ \\
\hline \multicolumn{3}{|c|}{ OPERACIONAL } \\
\hline
\end{tabular}

Figura 12. Aspectos operacionais do Plano diretor da Manutenção do FCSA.

Cinco temas são tratados como aspectos operacionais, Figura 12.

Os aspectos operacionais focam na forte padronização de todas as etapas do macrofluxo de manutenção e atividades relacionadas; nos treinamentos funcionais específicos por indivíduo; na manutenção preditiva integrada e eficiente (36 técnicas disponíveis); na revisão constante da criticidade dos equipamentos baseado no cenário mais atual de produção; e no registro único e inequívoco no CMMS como fator de valorização do histórico do equipamento e subsídio para análises futuras, principalmente relacionadas à engenharia de confiabilidade quantitativa [10].

\section{RESULTADOS E DISCUSSÃO}

O Plano Diretor de Manutenção e Gestão de Ativos da FCSA foi lançado oficialmente em 2013 com participação do corpo diretivo, gerencial e demais colaboradores. Esse plano, como as diretrizes corporativas está sendo utilizado pelas áreas de manutenção/operação como um guia. O documento está disponível para consulta via intranet para todos os empregados da ArcelorMittal Tubarão e ArcelorMittal Vega. A primeira rodada de auditorias de todas as áreas de manutenção do FCSA (25 áreas) ocorreu em 2013, sendo que atualmente está sendo realizado o coaching individualizado dessas áreas no intuito de tratar as oportunidades encontradas.

\section{CONCLUSÕES}

Conforme preconiza a norma ABNT NBR ISO 55000, a gestão de ativos é baseada nos seguintes fundamentos:

- Valor - Ativos existem para fornecer valor para a organização e suas partes interessadas.

- Alinhamento - A gestão de ativos traduz os objetivos organizacionais em decisões técnicas e financeiras, em planos e atividades.

- Liderança - Liderança e comprometimento de todos os níveis de gestão são essenciais para estabelecer com sucesso, operar e melhorar a gestão de ativos na organização.

- Garantia - A gestão de ativos garante que os ativos cumprirão com sua função requerida por um intervalo de tempo e condições de uso preestabelecidas [2].

A estruturação e implantação das diretrizes constantes no Plano Diretor de Manutenção e Gestão de Ativos traz grande sustentação para as áreas de manutenção e operação, sendo que no futuro será mais tranquila a implantação de uma norma de alto nível como a ABNT NBR ISO 55000, pois o foco está sendo na criação de políticas e diretrizes corporativas, capacitação de pessoas, registro do histórico dos equipamentos e planos de manutenção confiáveis sempre alinhado com a visão estratégica da empresa.

\footnotetext{
* Contribuição técnica ao 69ำ Congresso Anual da ABM - Internacional e ao 14ํㅡㄹ ENEMET - Encontro Nacional de Estudantes de Engenharia Metalúrgica, de Materiais e de Minas, 21 a 25 de julho de 2014, São Paulo, SP, Brasil.
} 


\section{REFERÊNCIAS}

1 Xavier JN. Gestão para Manutenção Classe Mundial. Belo Horizonte: Tecem tecnologia Empresarial; 2005.

2 Associação Brasileira de Normas Técnicas. ABNT NBR ISO 55000: Gestão de Ativos Visão Geral, Princípios e Terminologia. Rio de Janeiro; 2014.

3 Lafraia JRB. Roadmap do negócio sustentável: de manutenção a gestão de ativos. Revista Manutenção e Gestão de Ativos. Rio de Janeiro: ABRAMAN; 2013.

4 Associação Brasileira de Normas Técnicas. ABNT NBR ISO 55001: Gestão de Ativos Sistema de Gestão - Requisitos. Rio de Janeiro; 2014.

5 ArcelorMittal. Página da internet [acesso em 10 mar. 2014]. Disponível em: $<$ http://www.arcelormittal.com/br/tubarao>.

6 Kardec A, Xavier JN. Manutenção - Função Estratégica. 4ª edição. São Paulo: editora; 2012.

7 Institute of Asset Management. PAM - PAS 55 Assessment Methodology. Ano [acesso em 25 jul. 2013]. Disponível em: <https://theiam.org>.

8 Associação Brasileira de Normas Técnicas. ABNT NBR ISO 55002: Gestão de Ativos Sistema de Gestão - Diretrizes para a Aplicação da ABNT NBR ISO 55001. Rio de Janeiro; 2014.

9 Sodre R, Manoel J, Norberto J. Desenvolvimento do módulo de confiabilidade operacional no sistema informatizado de gestão da manutenção como fator estratégico rumo a manutenção classe mundial. In: $12^{\circ}$ Seminário Brasileiro de Confiabilidade na Manutenção; 2010; São Paulo, Brasil. São Paulo: Instituto de Engenharia; 2010.

10 Reliasoft Corporation. Análise de dados de vida. Presentation Handouts; 2012.

\footnotetext{
* Contribuição técnica ao $69^{\circ}$ Congresso Anual da ABM - Internacional e ao 14ํㅡㄹ ENEMET - Encontro Nacional de Estudantes de Engenharia Metalúrgica, de Materiais e de Minas, 21 a 25 de julho de 2014, São Paulo, SP, Brasil.
} 